\title{
Faking it or hating it: Can reflective practice be forced?
}

\author{
VALERIE HOBBS \\ University of Sheffield
}

\begin{abstract}
Many course providers in a variety of fields have chosen to include a required reflective practice assignment for purposes of instilling a spirit of professional development. However, the very notion of forced and evaluated self-exploration raises certain moral and practical issues that cannot be avoided. Relying on recent research at a Trinity College London TESOL Certificate course where course participants were required to complete a teaching practice journal, this article examines the problematic nature of required reflective practice, namely, that requiring individuals to be open and honest in the context of assessment tends to provoke strategic response and often hostility. These reactions, documented in other research as well, point to an underlying problem with any required reflection that has serious implications for teacher education as well as any other field that employs forced reflection.
\end{abstract}

Keywords: Teacher Education; Reflective Practice; ELT

*Email: v.hobbs@sheffield.ac.uk 


\section{Introduction}

While I was an undergraduate, a certain professor required our 'Self in Society' class to write a series of reflective essays designed to encourage us to examine negative patterns of behavior in our families, like loosely veiled racism or gender stereotyping, and thus become 'agents of change' in our generation. Because I had never before completed an assignment of this nature, my 'reflections' were superficial and guarded. Aside from the fact that I was unpracticed in such an exercise, the idea that my professor, whom I had only just met, would be reading my thoughts on extremely personal matters discouraged any genuine self-examination. I was not alone. Approximately three quarters of the class received poor marks for this assignment due to, in the professor's words, limited evidence of real reflection.

The use of 'reflective practice' as a means for personal development is not, however, exclusive to the field of sociology. The view of teachers as reflective practitioners has become increasingly prominent in the field of teacher education since Lortie (1975) first emphasized the importance of teachers' prior learning experiences, coining the phrase 'the apprenticeship of observation' and spawning an interest in the role that this plays in how teachers teach. Donald Schon (1983) added to the discussion by offering 'a new epistemology of practice' to the growing sense of need to delve into teachers' cognition, predicated on the notion that new situations are fathomed using the interplay between old and new experiences. Both Lortie's and Schon's concepts hinge on the fact that teachers, having spent thousands of hours as students, already possess deeply-held beliefs about what constitutes good and bad teaching, beliefs that are often rigid in the face of teacher education. In order to progress, then, teachers and teachers-in-training, in particular, must voice, confront, and evaluate these beliefs in the light of alternative models of teaching. As Moran \& Dallat (1995: 21) note, "Reflection...limits the impulsive nature of teaching and enables the educator to act with intention and deliberation."

Answering this call to reflective practice (RP), many course providers in a variety of fields have chosen to include an RP component. However, being critically self-aware is an acquired skill that 
comes with experience and great intellect (Moran \& Dallat, 1995; Hockly, 2000), and this being the case, not every individual is necessarily capable of engaging in critical reflection. Roberts (1998: 5859) argues that novice teachers, for example, have most often not yet explored or examined their own personal theories of teaching and learning and that reflection on 'borrowed' routines requires a depth of understanding that novice teachers just don't have. Even further, even where an individual has the capability of engaging in reflection, s/he may simply find RP distasteful or a waste of time. In the case of teacher education, Moore and Ash (2002) note, “...many new teachers choose not to reflect on their practice constructively and critically, preferring to fall back on pre-conceived understandings of how they and their pupils should conduct themselves in the classroom." After all, reflection is timeconsuming, and it's often just easier to rely on past experience.

This being said, the inclusion of RP in teacher education programs still remains largely undisputed (see Crandall, 2000; Freeman, 1993, 2001; Grenfell, 1998; Zeichner, 1994), warranting a closer look at how it is used as a learning process. Its implementation varies in different pre-service programs, sometimes taking the form of a teaching practice journal documenting a trainee's first experiences in the classroom, an autobiography documenting past learning experience and connecting it with present beliefs, an essay, or a group discussion with peers or tutors. Despite this variation, however, most of these manifestations of RP have at least one thing in common: they are all typically required assignments.

There can be no doubt that RP, when conducted with sincerity and thoroughness, can be a powerful means for enabling teachers, both novice and experienced, to examine critically their preconceptions about teaching and their effect on classroom decisions. However, there is some question as to whether or not RP can, in fact, be a required component of a course and still retain validity as genuine reflection. Can trainee teachers, or individuals for that matter, be forced to be reflective? Or, as some of the literature suggests (see Pecheone, et al., 2005; Roberts, 1998; Smith \& Lev-Ari, 2005), does the practice of RP for assessment purposes limit its effectiveness and/or 
authenticity? The following sections will explore how the required RP assignment in one pre-service ELT teacher education program seemed to provoke not only strategic 'reflection' but also a strong negative reaction from the majority of the trainees, thereby limiting the assignment's usefulness.

\section{Background to Discussion}

\section{a. Description of the Research Project}

This article arose out of research conducted in summer, 2005 at a four-week Trinity College London TESOL (Teachers of English to Speakers of Other Languages) Certificate course in the North of England (see Trinity College London 2004a, b for complete course description). This course is offered several times a year by a reputable university, referred to here as University of Britain (UoB). The primary aim of this research was to discover what effect, if any, short teaching certificate courses such as these have on the belief systems of novice ELT (English language teaching) teachers, although the collected data offered insight into a host of other issues associated with teacher education, such as the topic at hand.

Because existing research on short-term ELT teacher education often relies on interviews and questionnaires (see Green, 2005; Richards, Ho, and Giblin, 1996), which sometimes result in insincere data, I adopted a largely ethnographic research methodology, enrolling as a course participant. In this way, I gained access to the daily conversations and interactions of the other course participants and obtained insight into the actual daily experiences and stresses of individuals enrolled on an intensive course. Achieving this 'insider status' allowed me to be present during informal conversations between course participants, providing immensely rich data that illuminated the course participants' (CPs') genuine thoughts and ideas.

12 CPs acted as research participants, 6 men and 6 women, ranging in age from $23-61$ years. 6of the CPs had teaching experience, 2 having very limited ELT experience, and 6 had no prior teaching experience. Both the course provider and the CPs were informed of the nature and scope of 
the research and of their level of participation and right to withdraw, and all gave written consent that their comments and course assignments could be used as data.

Data was collected according to Denzin's (1978) framework of methodological triangulation and included field notes, audio-recorded informal interviews and conversations, questionnaires, course documents, CPs' teaching practice journals, and follow-up e-mails over the course of the year following the one-month program's completion. Several of these forms of data collection have been used in other studies on teacher beliefs (Bramald, et al., 1995; Kyriacou \& Cheng, 1993; Richards \& Pennington, 1998; Richards, Tung \& Ng, 1992; Bailey, et al., 1996; Grossman, 1995; Cortazzi, 1991; Woods, 1996), and employing as many data collection methods as possible enabled the acquisition of information about the participants' beliefs and experiences on the course from a variety of sources, reinforcing the validity of the research.

Although time constraints made ongoing data analysis during collection nearly impossible, research participants participated in data analysis in a limited fashion during the course itself in that they were asked to verify portions of data relevant to them. After the completion of the four-week course, data was meticulously read and then grouped into grounded categories using tables organized according to theme, research participant, time of collection, and type of data. The categories were then compared and cross-referenced numerous times, the frequency of occurrences and responses was tabulated, and the data was examined for deviant and negative cases.

\section{b. Overview of the Trinity College London TESOL Certificate}

The Trinity College London TESOL Certificate program advertises itself as an initial training program for those with little or no experience teaching English, focusing on practical teaching skills and emphasizing “...the basic skills and knowledge needed to take up a first post as an ESOL teacher..." (Trinity College London, 2004a: 6). These are structured around five units which 
incorporate all the required learning objectives. These units include (Trinity College London, 2004b: 18):

- Teaching skills (including methodology, teaching practice, guided observation, materials evaluation, etc.)

- Language awareness (grammar and phonology)

- The learner profile (a simple linguistic profile and needs analysis for one learner of English)

- The materials assignment (planning, producing, using, and evaluating classroom materials)

- Unknown language

The primary RP assignment falls under the category of 'Teaching Skills' and takes the form of journal where course participants write about their classroom experiences while on the course. Although the program also requires RP in the form of a language learning journal (as part of the 'Unknown Language' component) and teaching practice feedback sessions with tutors, the Teaching Practice or TP Journal is the focus of this article, primarily because it was weighted more heavily in terms of course assessment and generated more data from the CPs on the UoB course.

\section{Required Reflective Practice: The Teaching Practice Journal Assignment}

The Trinity TESOL Certificate course requires a TP journal with the rationale that successful CPs will thus exhibit "the potential to assess their own strengths and weaknesses in order to benefit from further training and assist in the evaluation of their peers" (Trinity College London, 2004b: 19). Trinity College's Validation Guidelines (ibid., p. 21) specify what the TP journal assignment must include (see Table 1). For the UoB's TESOL Certificate course, these guidelines translate to very detailed pro-formas for each journal entry, which CPs are required to complete both before and after teaching each lesson. Each lesson's set contains different questions, asking CPs to focus on different 
aspects of their teaching, such as instructions, classroom management, or effectiveness of materials

(see Table 2). In this way, CPs are guided to be reflective in specific ways in regards to their teaching.

Table 1. The Contents of the Teaching Practice Journal (Trinity College London, 2004b: 21).

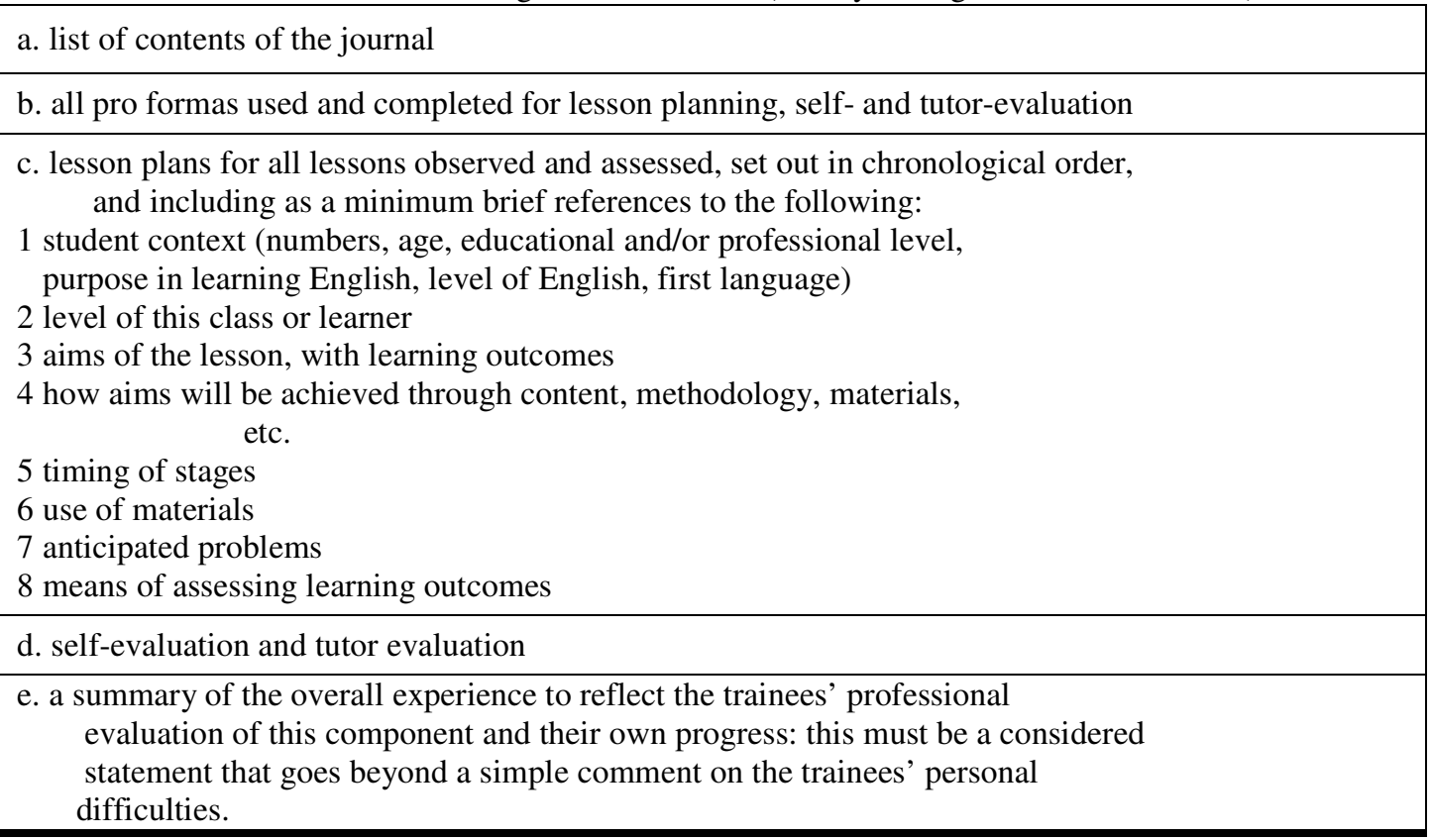

Table 2. Examples of UoB's Teaching Practice Journal Questions/ Prompts

\begin{tabular}{|l|l|}
\hline No. & \multicolumn{1}{|c|}{ Examples of TP Journal Questions/ Prompts } \\
\hline 1 & What are your objectives in this lesson? \\
\hline 2 & How are the stages of the whole lesson linked together to meet overall objectives? \\
\hline 3 & $\begin{array}{l}\text { What is the single most important point you learned about each of this: yourself as a teacher, your } \\
\text { learners, classroom teaching? }\end{array}$ \\
\hline 4 & $\begin{array}{l}\text { Summarize the main things you have learned about classroom language from this lesson and the } \\
\text { discussion with the tutor. }\end{array}$ \\
\hline 5 & What if anything would you change about this lesson and how? \\
\hline 6 & What parts were you particularly pleased with and why? \\
\hline 7 & What did you most enjoy about teaching this lesson? \\
\hline 8 & What parts were you less happy about and why? \\
\hline 9 & Summarize the effectiveness of your instructions in this lesson... \\
\hline 10 & $\begin{array}{l}\text { Comment on your personal development as a teacher during this course. What are the 2 most } \\
\text { valuable lessons you have learned during your teaching experiences here? }\end{array}$ \\
\hline
\end{tabular}

The inclusion of all lesson plans, materials, and feedback pro-forma in the TP Journal is designed primarily to give CPs an organized and thorough record of their teaching practice both for 
future reference and, hopefully, as a way of engaging in ongoing development throughout the course. Sounds promising. However, certain problems inherent in the UoB's reflective journal design, namely, the journal's leading and repetitive writing prompts, raise questions regarding the validity and effectiveness of this manifestation of forced RP. Furthermore, the CPs strong negative reaction to the idea of being forced to be reflective, a reaction documented in other research as well (see Smith \& LevAri, 2005), points to an underlying problem with any required reflection that has serious implications for teacher education.

\section{Problems with the Teaching Practice Journal}

\section{a. Leading and Repetitive Writing Prompts Resulting in Strategic Response}

Pecheone, et al. (2005) aptly note a common methodological limitation of using required reflective assignments for assessment purposes. They write, "The reliability of artifacts from the portfolio assessment alone as evidence of teacher learning is questionable because teachers know they will be evaluated on the basis of these artifacts for their "reflectivity." Knowing that increased evidence of reflection will achieve a better response (and a better mark) from the tutors, CPs are often tempted to write strategic journal entries. Roberts (1998: 59) elaborates on the cause for inauthentic reflection, noting that it stems from the use of RP as a form of assessment. "Assessment demands the meeting of external requirements and the disguise of personal weaknesses; neither condition is productive of reflection on aspects of self in need of change." In other words, it's instinctual to downplay one's faults and accentuate one's strengths when being assessed or analyzed. When one is asked to reflect on his/her strengths and weaknesses as part of a required, graded course assignment, it seems, then, that genuine examination of self is already a lost cause.

This was most certainly the case in the UoB TP Journal assignment. The use of RP for assessment purposes created immense pressure on course participants to write 'display journal entries' to please the course tutors. The CPs commented on this pressure during several conversations during 
the course, the following excerpt serving as an example of one CP's relief that the tutor had given him positive feedback in regards to his journal.

I just uh sortof sit in the car and just write on it. But I was sortof reassured when [the tutor] looked at my teaching sortof journal and sifted- flipping over and saying well, it's quite detailed, and we talked about it, and that's fine, and you know. Yeah, I'm sortof - yeah, I mean, when someone has actually sortof said you've done it, and that's what we want...

Another $\mathrm{CP}$ offered the following comment during a discussion among the CPs regarding how to discover the tutors' criteria for a 'good lesson plan,' which had to be included in the TP Journal Assignment.

I showed [the tutor] my lesson plan, and she said, Oh, yes, that means that the objectives is so and such and so and such and so and such. And I said: can I write that down, and she said yes, that would be a good thing to write. That's the way of doing objectives... and this is what we learn. You're far better off when they say they want to see your final plan, you give them a few ideas, (laughs) and then they put them together and tell you how to teach it.

However, even beyond this initial pressure to please the tutors which was inherent in the assignment itself, the structure of this particular RP assignment compounded the problem of strategic response as writing prompts were leading and suggestive. As some of the examples from the journal questions demonstrate (see Table 2), the guidance that the UoB TP Journal offered also often acted as a prompt for only a certain type of answer, leading the CP to describe and then 'reflect' on his/her lesson a certain way even if the lesson was not this way.

The first example of this comes at the beginning of the TP Journal, where, before any reflection on individual lessons occurs, CPs must complete two 'observation' pages after each of two nights of observing an 'experienced' teacher. The final set of prompts for each observation journal entry requires that CPs elaborate on the extent to which their observations coincided with those of other CPs. However, as with other assignments requiring collaboration on the course, most CPs ended up writing entries like "Yes, we all agreed" without discussing it with anyone else. Three of the CPs remarked on 
the last day of the course that there wasn't always time to consult with one another and that because no one was ensuring that collaboration occurred, it was easy enough to 'fake it.'

Further examples of leading prompts eliciting strategic entries pervade the CPs' journals. For example, one prompt required CPs to discuss briefly how each of their individual lesson's activities built on the previous one and/or prepared for the next. In the case of several of the CPs' responses, it seemed too tempting simply to describe their lesson's activities as well-connected even if they were not. For example, two of the CPs conducted lessons marked by constant spontaneity, and, in private conversations, both expressed dislike at writing lesson plans because they felt that a lesson should be driven by student-initiated questions and responses rather than teacher-imposed activities. As one of the CPs put it "What you find is that you don't need to plan your lesson so much because they [the students] sortof take control, don't they?" Nevertheless, some of these two CPs' journal entries describe lessons whose activities were meticulously planned to build on previous ones, despite the fact that these same lesson plans most often bore no resemblance to what actually occurred in the classroom. The CPs' comments in casual conversation reinforced this contradiction, both of them remarking several times that little advanced planning had taken place and that they simply let the lesson go where the students took it.

In addition to the often strategic journal entries, inconsistencies within the CPs' journal entries also serve as evidence that the format of the journal was perhaps too leading. One CP's journal entries, for example, show clear inconsistencies which seem to stem at least partly from the format of the journal prompts (see Table 3). Her entries for lesson \#5 are the most telling in that she makes two opposing statements in the same journal entry, commenting both on the weakness of her instructions and later on the fact that she has no problem giving instructions. The format of the journal seems, in some ways, to lead her to do this, the prompt asking her to summarize her progress as a teacher, requiring her to show some evidence of development. 
Not all of the CPs' TP Journals showed inconsistencies, and some showed evidence of genuine attempts at reflection. Two of the CPs' journals, in particular, were far removed from the formulaic style of many of the other CPs and contained no blaring inconsistencies. However, the repetitive nature of the prompts and questions (with some being repeated in every lesson's entry) struck a chord with even these CPs at some point, who demonstrated frustration with entries like "I already answered that" or "See previous question." This negative attitude towards the TP journal, perhaps stemming in part from the structure of the journal, largely limited the effectiveness of this RP assignment and will be explored in the next section.

Table 3. Inconsistent Journal Entries

\begin{tabular}{|c|c|}
\hline Lesson \#3: & Journal Entry \\
\hline $\begin{array}{c}\text { What, if any, further modifications might you make to } \\
\text { the lesson plan or execution in the light of your } \\
\text { discussions [with the observing tutor]? }\end{array}$ & "Need to improve on instructions..." \\
\hline $\begin{array}{c}\text { Lesson \#4: } \\
\text { In note form, list the personal strengths you } \\
\text { can build on in future lessons. }\end{array}$ & $\begin{array}{c}\text { Listed her best personal strength as "Clear } \\
\text { instructions" }\end{array}$ \\
\hline $\begin{array}{c}\text { Lesson \#5: } \\
\text { What was most instructive about tutor feedback? }\end{array}$ & $\begin{array}{c}\text { "I still need to work on my instructions" } \\
\text { teacher. }\end{array}$ \\
\hline
\end{tabular}

\section{b. Negative Attitudes toward the Teaching Practice Journal}

Some of the literature on RP suggests that a negative attitude towards required reflection in the context of teacher education is quite common. Smith \& Lev-Ari (2005), for example, found that only a third of the 480 student teachers who participated in their research found the reflective teaching journal assignment to be effective as an instrument for exploring teaching and learning experience. Roberts (1998: 59) writes that initial teacher education participants often adopt a negative attitude towards 
reflective assignments because they view them as "imposed course requirements, with no real meaning for themselves."

As previously discussed, the CPs' comments in conversation and inconsistent journal entries indicate that they often adopted an insincere outlook towards the journal. However, in addition, all of the CPs expressed a negative attitude towards the TP journal, the experienced teachers' resenting having to engage in reflection about their teaching and those with no teaching experience viewing it as a waste of time. At one point, one of the CPs offered "to give people lessons in sortof blabbety blah...", suggesting that he was not taking the journal seriously. That same day, he noted that he had resorted to a formula which he followed every time. A conversation between two of the experienced teachers again demonstrates their dislike of the TP Journal.

CP1: ...I didn't see the point of filling out all those bits of paper though so I sortof told him [the tutor] I had given him an edited version [of the TP Journal] and left bits out.

CP2: yeah, it's ideal, because we're already teachers really - the two of us

CP1: Oh, gosh, Yeah, cause what do we need with all these bits of paper? XXX we have years and years of classes, and so I feel badly writing all this out.

When I asked one of the inexperienced teachers about his approach to completing the teaching journal, he replied, "Some of them it's just like a line...[Sometimes I] just leave it blank. Can't say I care about this." In fact, he left out whole sections of the teaching practice journal as several other CPs did, starting sentences without completing their thoughts and generally writing the same ideas over and over using slightly different wording.

The data indicates that the CPs generally saw most of the assignments, with the exception of the teaching practice, as a waste of time. They had enrolled on the course to gain confidence and experience in the classroom and resented being forced to use valuable time to complete assignments whose purposes they didn't understand. However, the unique dislike they demonstrated for the required TP Journal assignment, about which they complained consistently, points to serious limitations on any impact that this RP assignment might have had on their self development. 


\section{Discussion}

The question regarding whether or not forced RP is truly useful as a learning tool is relevant to more fields of inquiry than just teacher education. Hargreaves (2004: 196), while recognizing that RP is crucial for health care training, writes that the pressure to perform well academically discourages honest and uninhibited reflection. She goes on to point out that many of the problems associated with assessed reflection stem from a lack of advice in the literature regarding how best to assess reflection. Her conclusion is that reflection and assessment are simply incompatible, "Reflection in isolation is a fairly ambiguous moral exercise, but not when it is used explicitly within professional education as a medium for developing the affective professional and personal attributes associated with being a competent and acceptable practitioner" (p. 200). As my own data suggests, required RP in ELT teacher education, as well, raises similar moral issues that, I believe, provoked the negative response from UoB's course participants. It seems only natural to feel resentment towards a stipulation that asks one to be open and honest about one's beliefs whilst implying that a certain response is preferable. Course participants are really only given two options: choose to reveal only those ideas that the assessor might look on favorably or else generate strategic beliefs and opinions. Both have the potential to evoke a negative response. Certainly, collection of research data in the form of reflective writing also raises ethical dilemmas where research participants may feel pressured to display beliefs or attitudes preferable to the researcher. However, in the case of this project, the framework of participant observation and repeated assurance that that the journals would not be 'evaluated' by the researcher promoted an atmosphere of trust and equality that downplayed any perceived power distance between the researcher and the CPs that might've otherwise contributed to feelings of pressure to perform for the researcher.

Some writers, (see Fernsten \& Fernsten, 2005) argue that required RP can be an effective learning process where a 'safe and supportive environment' exists and where students are not punished with lower grades or reprimands for RP assignments that fail to meet a certain standard. In the case of 
UoB's RP assignment, some attempt was made to create this safe environment by means of a assessment grid that focused not on how well each $\mathrm{CP}$ reflected the ideologies of the course tutors but on evidence of 'clarity of journal, 'quality of insight for learning and teaching issues,' and 'ability to prioritize areas for improvement.' This grid was available in the course handbook for all CPs to view at any time during the course. However, when asked if they had looked at the grid at any point before turning in their TP Journal, the CPs said they had not, and the conversations they had during the course point clearly to their belief that the tutors were looking for certain answers and that providing such answers would result in a better mark. Of course, increased communication between tutors and CPs might have remedied this problem to some extent. However, in the context of an intensive teacher training course, restrictions on time often result in a reliance on paperwork to provide explanation of course procedures, and in this context, the large amount of paperwork given to the CPs was overwhelming and the miscommunication thus understandable. However, even had the tutors explicitly explained this assessment grid during the course, trainees might simply have disregarded this information in light of the stressful nature of the course and the quantity of information they were already required to remember. This raises further issues about short courses that will not be dealt with here but certainly warrant discussion elsewhere. Nevertheless, the fact that the CPs' belief about RP assessment was not necessarily grounded in reality is irrelevant. What is highly relevant is that this belief, which seemed to go unnoticed and unchecked by the course tutors, had a powerful impact on the types of journal entries they composed and led them to think less about genuine reflection and more about pleasing the tutors or just completing the assignment.

\section{Conclusions}

Returning to my own initial experience with required RP discussed in the introduction, I quickly learned from my undergraduate professor that in spite of my inexperience with selfexamination and my inhibitions about revealing personal thoughts to a virtual stranger, I had damned 
well better produce what the professor wanted to see if I wanted a good grade. In subsequent essays, I therefore resorted to strategic deception, revealing carefully contrived stories about the negative effects of sibling rivalry on my family over the generations. Uncomfortable with revealing my family's genuine faults, I constructed fairly harmless ones, which awarded me the marks I wanted without sacrificing my dignity. Rather than a process towards self-development, this assignment became merely an exercise in perfecting my ability to anticipate what the professor wanted and to give it to him.

Along these lines, Hargreaves (2004) argues that forced self-examination can really never be a positive learning tool. She contends that because RP is so important for self-growth, it should indeed be required by course providers but that it must be separated from the individual, instead taking the form of assignments like reflecting on a fictional narrative. However, Hargreaves' conclusions aren't really applicable for teacher education. After all, it is a teacher's personal beliefs that influence his/her classroom decisions, and reflection must therefore be a personal experience. As Griffiths \& Tann (1992) point out, "reflection on one's own...theories is precisely what distinguishes the reflective practitioner model."

So what then? Creating a forced RP assignment that evokes genuine and uninhibited response is a difficult undertaking. In my opinion, it is nearly impossible. The reality is that even where a supportive environment rather than the grade is prioritized, individuals, by nature, tend to believe that writing ideas that their superiors agree with or view as intelligent and meaningful will have a positive effect on their grade or position. For this reason and based on the importance of RP in teacher education as well as my experiences with forced RP at UoB, I would argue in favor of several conclusions. First, RP should be introduced slowly, with only the barest minimum of reflection required on the part of initial teacher trainees. Being forced to reflect, particularly in the form of a substantial assignment early on, is too much too quickly, increasing the likelihood of resentment and negativity. Possibilities could include timetabled discussions with other course participants where perhaps a one-word prompt could be introduced by a tutor who either leaves the room or monitors from 
a distance. Second, given the personal nature of RP, course participants should be actively involved in choosing the format of their RP assignment. As in the case of UoB, the CPs resented being forced to reflect in a format they disliked and may have responded more positively to the assignment had they been given more choices like a group discussion format or a written format of their own choosing.

Finally, RP should never be assessed in its early stages. Individuals should be given opportunity to gain confidence and awareness in a non-threatening atmosphere; only after they have acquired significant experience with engaging in RP should any assessment be considered.

$\mathrm{RP}$ is an important self-development process and should be encouraged in teachers, in health care professionals, in managers, and in any field whose members work with other people. However, the notion of requiring self-examination raises moral and practical questions which must be examined carefully. Hopefully, the suggestions offered here, based on one example of an RP assignment, will provoke further discussion on this matter and cause course providers to think twice when implementing required reflection.

\section{Author's Biography:}

Valerie Hobbs is a Postgraduate Research Student and Teaching Fellow in the department of English Language and Linguistics at the University of Sheffield. Her PhD research focuses on short-term ELT teacher education and its impact on teacher beliefs. She has presented her research at several conferences, including TESOL, IATEFL, BAAL, and the annual Ethnography in Education Research Forum at the University of Pennsylvania.

\section{References}

Bailey, K. M.; Bergthold, B.; Braunstein, B.; Fleischman, N. J.; Holbrook, M. P.; \& Tuman, J. (1996) The language learner's autobiography: Examining the "apprenticeship of observation", in: Freeman, D \& Richards, JC (Eds) Teacher learning in language teaching (Cambridge; New York, Cambridge University Press), 11-29.

Bramald, R., Hardman, F., \& Leat, D. (1995) Initial teacher trainees and their views of teaching and learning, Teaching and Teacher Education, 11(1), 23-31.

Cortazzi, M. (1991) Primary Teaching How It Is: A narrative account (London, Fulton).

Crandall, J. (2000) Language Teacher Education, Annual Review of Applied Linguistics, 20, 34-55.

Denzin, N. K. (1978) Sociological methods: A source book (New York, McGraw Hill).

Fernsten, L., \& Fernsten, J. (2005) Portfolio assessment and reflection: enhancing learning through 
effective practice, Reflective Practice, 6(2), 303-309.

Freeman, D. (1993) Renaming experience/ reconstructing practice: Developing new understandings of teaching, Teaching and Teacher Education, 9(5-6), 485-497.

Freeman, D. (2001) Second language teacher education, in: Carter, R. \& Nunan, D. (Ed) The Cambridge guide to teaching English to speakers of other Languages, (Cambridge, Cambridge University Press), 72-79.

Green, T. (2005) Staying in touch: Tracking the career paths of CELTA graduates, Research Notes, 19, 7-11.

Grenfell, M. (1998) Training teachers in practice (Clevedon, UK, Multilingual Matters).

Griffiths, M. \& Tann, S. (1992) Using reflective practice to link personal and public Theories, Journal of Education for Teaching, 18(1), 69-84.

Grossman, P. L. (1995) Teacher's Knowledge, in: Anderson, L.W. (Ed) International Encyclopedia of Teaching and Teacher Education, (Cambridge, Cambridge University Press), 20-24.

Hargreaves, J. (2004) So how do you feel about that? Assessing reflective practice, Nurse Education Today, 23(3), 196-201.

Hockly, N. (2000) Modeling and 'cognitive apprenticeship' in teacher education, ELT Journal, 43(2), 118-125.

Kyriacou, C., \& Cheng, H (1993) Student teachers' attitudes toward the humanistic approach to teaching and learning in schools. European Journal of Teacher Education, 16(2), 163-168.

Lortie, D. (1975) Schoolteacher (Chicago, University of Chicago Press).

Moore, A., \& Ash, A. (2002) Reflective practice in beginning teachers: helps, hindrances and the role of the critical other. Available online at: http://wwwleedsacuk/educol/documents/00002531htm (accessed 26 June, 2006).

Moran, A., \& Dallat, J. (1995) Promoting reflective practice in initial teacher training, International Journal of Educational Management, 9(5), 20-26.

Pecheone, R. L.; Pigg, M.; Chung, R. R.; \& Souviney, R. J. (Mar/April 2005) Performance assessment and electronic portfolios: Their effect on teacher learning and education, The Clearing House, 78(4), 164-176.

Richards, J. C.; Ho, B.; \& Giblin, K. (1996) Learning how to teach in the RSA Cert, in: Freeman, D. \& Richards, J.C. (Eds) Teacher learning in language teaching, (New York, Cambridge University Press), 242-259.

Richards, J. C., \& Pennington, M. C. (1998) The first year of teaching, in: Richards, J.C. (Ed) Beyond Training, (Cambridge; New York, Cambridge University Press), 173-190.

Richards, J. C.; Tung, P.; \& Ng, P. (1992) The culture of the English language teacher: A Hong Kong example, RELC Journal, 23(1), 81- 103.

Roberts, J. (1998) Language Teacher Education (London, Arnold).

Schon, D. A. (1983) The reflective practitioner: how professionals think in action (New York, Basic Books).

Smith, K., \& Lev-Ari, L. (2005) The place of the practicum in pre-service teacher education: The voice of the students, Asia-Pacific Journal of Teacher Education, 33(3), 289-302.

Trinity College London (2004a) Certificate in Teaching English to Speakers of Other Languages: A summary of course content and key information for course members. Available online at: http://wwwtrinitycollegecouk/_downloads/TESOL/documents/certTESOL_Summarypdf (accessed 1 December, 2004).

Trinity College London (2004b) Certificate in Teaching English to Speakers of Other Languages: Validation requirements for validated and prospective course providers. Available online at: http://wwwtrinitycollegecouk/_downloads/TESOL/documents/CertTESOL_Validation_Require mentspdf (accessed 1 December, 2004).

Woods, D. (1996) Teacher cognition in language teaching: Beliefs, decision-making and classroom 
practice (New York, Cambridge University Press).

Zeichner, K. M. (1994) Reflective practice in teaching, in: Harvard, G.R. \& Hodkinson, P. (Eds) Action and reflection in teacher education (Norwood, NJ, Albex Publishing Corporation), 15- 34. 